\title{
In situ observations of microscale damage evolution in unidirectional natural fibre composites
}

Rask, Morten; Madsen, Bo; Sørensen, Bent F.; Fife, Julie L.; Martyniuk, Karolina; Lauridsen, Erik Mejdal

Published in:

Composites - Part A: Applied Science and Manufacturing

Link to article, DOI:

10.1016/j.compositesa.2012.02.007

Publication date:

2012

Link back to DTU Orbit

Citation (APA):

Rask, M., Madsen, B., Sørensen, B. F., Fife, J. L., Martyniuk, K., \& Lauridsen, E. M. (2012). In situ observations of microscale damage evolution in unidirectional natural fibre composites. Composites - Part A: Applied Science and Manufacturing, 43(10), 1639-1649. https://doi.org/10.1016/j.compositesa.2012.02.007

\section{General rights}

Copyright and moral rights for the publications made accessible in the public portal are retained by the authors and/or other copyright owners and it is a condition of accessing publications that users recognise and abide by the legal requirements associated with these rights.

- Users may download and print one copy of any publication from the public portal for the purpose of private study or research.

- You may not further distribute the material or use it for any profit-making activity or commercial gain

- You may freely distribute the URL identifying the publication in the public portal 


\title{
In situ Observations of Microscale Damage Evolution in Unidirectional Natural Fibre Composites
}

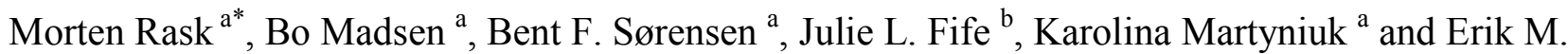 \\ Lauridsen $^{\text {a }}$ \\ ${ }^{a}$ Department of Wind Energy, Risø Campus, Technical University of Denmark, 4000 Roskilde, \\ Denmark \\ ${ }^{\mathrm{b}}$ Swiss Light Source, Paul Scherrer Institut, 5232 Villigen, Switzerland
}

* Corresponding author:

Department of Wind Energy, Risø Campus, Technical University of Denmark, Building 228, Frederiksborgvej 399, 4000 Roskilde, Denmark

Tel.: +45 4677 5843; E-mail: mrask@dtu.dk 


\begin{abstract}
Synchrotron X-ray tomographic microscopy (XTM) has been used to observe in situ damage evolution in unidirectional flax fibre yarn/polypropylene composites loaded in uniaxial tension at stress levels between $20 \%$ and $95 \%$ of the ultimate failure stress. XTM allows for 3D visualization of the internal damage state at each stress level. The overall aim of the study is to gain a better understanding of the damage mechanisms in natural fibre composites. This is necessary if they are to be optimized to fulfil their promising potential. Three dominating damage mechanisms have been identified: (i) interface splitting cracks typically seen at the interfaces of bundles of unseparated fibres, (ii) matrix shear cracks, and (iii) fibre failures typically seen at fibre defects. Based on the findings in the present study, well separated fibres with a low number of defects are recommended for composite reinforcements.
\end{abstract}

\title{
Keywords
}
A. Flax fibres
B. Fracture B. Microstructures
D. Synchrotron X-ray tomography

\section{Introduction}

Motivated by the growing awareness of occurring and imminent climate changes, an increasing amount of interest has been focused on replacing traditional solutions with sustainable alternatives. This tendency is also seen in materials science, where attempts are being made to replace traditional fossil based materials with natural derived counterparts [1]. As such, the present study is carried out with the overall purpose of contributing to optimize natural fibre composites for load-bearing applications. This is an area with great potential, as the theoretical reinforcement capability of natural fibres indicates that they can be a competitive alternative to traditional glass fibres [2]. Presently, the strength of natural fibres composites is not as high as expected based on the findings from single fibre tests, where natural 
fibres show strength properties of up to $1800 \mathrm{MPa}$ [3]. In order to understand why these fibre strength properties are not fully utilized in composites, it is necessary to gain further insight into the strengthcontrolling failure mechanisms in the composites.

Natural fibres such as hemp and flax are obtained from the stems of the respective plants. Depending of the application, the fibres can be separated into individual fibres (sometimes referred to as fibre ultimates), or into fibre bundles (sometimes referred to as technical fibres) consisting of 5-500 individual fibres [4]. The fibre bundles are composed of individual fibres kept together mainly by pectins, meaning that the fibre bundles themselves are actually composite structures. Fibre bundles have diameters of 30-300 $\mu \mathrm{m}$, while individual fibres have diameters of 15-35 $\mu \mathrm{m}$. Whereas synthetic fibres used for composite reinforcement (e.g. glass and carbon) are handled in rovings, in which the continuous fibres are arranged in a parallel fashion, this can not be done for natural fibres due to their short lengths in the range 5-50 $\mathrm{mm}$ for hemp and flax fibres. Instead, a loose assembly of parallel fibres are twisted to form a fibre yarn, in which the integrity of the fibre assembly is maintained by the internal friction forces between individual fibres. These fibre yarns with typical diameters of 300-2000 $\mu \mathrm{m}$ are not to be confused with the fibre bundles. The relations between fibre yarns, fibre bundles and individual fibres are illustrated schematically in Figure 1.

The failure mechanism of a fibre is related to its brittleness. The failure of brittle fibres like glass fibres is to a large extent controlled by defects in the fibres, and may best be described by Weibull statistics [5]. It is known that the strength and failure mechanism of natural fibres are also largely affected by the presence of defects $[3,6]$. The field of study of defects in natural fibres is still developing, and the terminology is not yet fully developed. It is known that flax fibres have some localized structural 
irregularities in their cell walls, sometimes referred to as kink bands, dislocations or nodes [7]. In the present study they will be referred to simply as defects. It is widely believed that such defects are formed by excessive compressive loading (e.g. excessive bending) of the fibre during handling and processing, resulting in local disorganization of the otherwise well-aligned cellulose microfibrils in the cell wall of the natural fibres $[8,9]$. In composite materials, such fibre defects are known to be weak nodes giving rise to stress concentrations in the surrounding matrix, and ultimately fibre failure during tensile loading [10].

In order to achieve stronger natural fibre composites, it is necessary to understand the damage mechanisms of these materials. As such, in this study, the three-dimensional microstructural damage evolution of unidirectional (UD) natural fibre composites is studied in situ during loading until failure. Synchrotron X-ray tomographic microscopy (XTM) has proven itself a valuable tool for investigations of failure mechanisms in conventional fossil based composites materials [11, 12]. In the present study, in situ XTM observations were made of notched specimens of UD flax fibre/polypropylene composites at a number of load steps during uniaxial tension tests.

\section{Materials and methods}

Flax fibre yarns with a linear density of $110 \mathrm{~g} / \mathrm{km}$ and a twist number of 313 turns per meter, giving a surface twisting angle of about $18^{\circ}$ were supplied by Ekotex, Poland. The thermoplastic polymer, polypropylene (PP) supplied by Comfil, Denmark, was used as matrix material in the form of filaments with a linear density of $51 \mathrm{~g} / \mathrm{km}$. PP was chosen as matrix material since it has a relatively low density of $0.91 \mathrm{~g} / \mathrm{cm}^{3}$ compared with the higher density of $1.55 \mathrm{~g} / \mathrm{cm}^{3}$ for flax fibres, in order to have the best possible contrast in the XTM experiments. 


\subsection{Description of composite manufacturing}

The composite panels were manufactured by filament winding followed by press consolidation [13]. The advantage of filament winding is that it allows for manufacturing of unidirectional composites with a very high degree $\left( \pm 1^{\circ}\right)$ of fibre yarn alignment. Flax fibre yarns and PP matrix filaments were wound together on a steel frame of dimensions $450 \times 500 \mathrm{~mm}^{2}$. The number of fibre yarns and matrix filaments was such that a fibre volume fraction of 0.37 was attained in the final composite panel. Following the filament winding, the fibre/matrix assembly was dried under vacuum for 24 hours at room temperature to remove humidity from the natural fibres. The assembly was then processed in two steps. Firstly, the fibre/matrix assembly was heated to $190^{\circ} \mathrm{C}$ for $15 \mathrm{~min}$ to melt the PP matrix. This was done under vacuum to avoid entrapment of air. Secondly, the assembly was press consolidated for $1 \mathrm{~min}$ at $30^{\circ} \mathrm{C}$ at a pressure of $800 \mathrm{kPa}$. The dimensions of the manufactured composite panel were 250 x $400 \mathrm{~mm}^{2}$, with a thickness of $2.9 \mathrm{~mm}$.

\subsection{Description of test specimens}

Performing high resolution XTM scanning puts some limitations on the dimensions of the test

specimens. In the present study, test specimens of dimensions $70 \times 3 \times 1 \mathrm{~mm}^{3}$ were used. The geometry and the dimensions of the test specimens, as well as the orientation with respect to a coordinate system are shown in Figure 2a. The test specimens were cut from the composite panel with the tensile axis along the fibre yarn axis. The specimens were grinded and polished to a thickness of $1 \mathrm{~mm}$. In order to ensure that damage developed in a well-localized region, the specimens were notched. The notches are half circles made using a $2 \mathrm{~mm}$ end mill, resulting in a nominal $1 \times 1 \mathrm{~mm}^{2}$ square cross section at the middle of the notched region. Aluminium tabs were glued with a cyanoacrylate adhesive at each end of the specimens to facilitate fixing the specimens in the loading fixture. 


\subsection{Description of tensile testing procedure}

A custom-built loading fixture was used for XTM in situ tensile testing [14]. The fixture is small and light, but capable of applying a tensile force up to $1.5 \mathrm{kN}$. The part of the fixture being exposed to the $\mathrm{X}$-ray beam is made from polymethyl methacrylate for minimal beam attenuation. The top of the fixture features a hex screw, which can be manually turned to control the displacement applied to the specimen, thereby loading the specimen. The applied force was measured at a rate of $1 \mathrm{~Hz}$ with a builtin $1.5 \mathrm{kN}$ load cell. The load was converted to a nominal stress value, calculated as the applied force divided by the cross sectional area at the middle of the notched region $\left(=1 \times 1 \mathrm{~mm}^{2}\right)$. The specimens were scanned by XTM at nominal stress values of $0,20,35,60,70,80,90,100$ and $110 \mathrm{MPa}$. The notched geometry of the specimen makes a non-uniform stress field, hence the term 'nominal'. At each load step, after applying the desired load, the specimen was unloaded by $25 \%$ to prevent evolution of further damage to the specimen during scanning, which would result in blurry images. Henceforward, when referring to a certain stress level, it means that the specimen was loaded to that stress level and was then unloaded by $25 \%$. Five specimens were tested to failure during XTM scanning.

\subsection{Preliminary tests}

Preliminary tensile tests were performed to validate that the specimens developed damage in the notched region. Monotonic tensile tests were performed on a standard hydraulic tensile testing machine at a displacement rate of $0.5 \mathrm{~mm} / \mathrm{min}$. During these tests, the specimens were equipped with acoustic emission equipment in order to select the appropriate stress levels for the observation of damage evolution from zero stress to the final failure stress. Two samples were tested, and they both failed in the notched region with ultimate strengths of $161 \mathrm{MPa}$ and $169 \mathrm{MPa}$. 
Another series of laboratory tests were performed to simulate the step-wise load sequence used at the synchrotron facility. The specimens were loaded to 60, 90, 120 and $150 \mathrm{MPa}$. Following each load step, the specimens were subsequently unloaded by $25 \%$ and kept at constant displacement for $30 \mathrm{~min}$. Two samples were tested and ultimate strengths of $111 \mathrm{MPa}$ and $140 \mathrm{MPa}$ were found.

\subsection{Description of beamline and data acquisition}

The XTM experiments were conducted at the TOMCAT beamline located at the X02DA port of the Swiss Light Source at the Paul Scherrer Institut, Switzerland. An X-ray photon energy of $25 \mathrm{keV}$ was used, with $700 \mathrm{~ms}$ exposure times, and 1501 projections were captured over the $180^{\circ}$ of rotation. The detector was a Ce-doped LAG scintillator with a thickness of $25 \mu \mathrm{m}$, and a 2048 x 2048 pixel CCD camera with a 280c digital/analog converter and a $10 \mathrm{MHz}$ read-out speed. The loading fixture was mounted on the sample stage and a total of 2048 slices, with a spatial resolution of $0.74 \times 0.74 \times 0.74$ $\mu \mathrm{m}^{3} /$ voxel, were collected at each load step. This corresponds to a scanned volume of $1.48 \times 1.48 \mathrm{x}$ $1.48 \mathrm{~mm}^{3}$, which was centred at the notched region of the specimen. The method of inline phase contrast tomography utilizing the Modified Bronnikov Algorithm [15] was employed to enhance the visibility of the interfaces.

Prior to the analysis of the failure evolution, the reconstructed 3D volumes corresponding to each load step needed to be aligned with respect to each other. In order to reduce the computational requirements

associated with the alignment process, the 3D volumes were resampled to $1024^{3}$ voxels, with a voxel size of $1.48 \mu \mathrm{m}$, using the Lanczos filter in the Avizo software [16]. The resampled volumes were subsequently aligned based on the Avizo registration tool utilizing normalized mutual information. 


\subsection{Scanning electron microscopy}

Scanning electron microscope (SEM) images of the flax fibre yarn were made with a Hitachi TM-1000 table-top SEM. Yarn samples were attached to a standard specimen holder with double-sided adhesive carbon tape. The samples were not coated, as the SEM was run in charge-reduction mode which minimizes charge build-up.

\section{Results}

\subsection{Undamaged microstructure}

Figure $2 \mathrm{~b}$ shows an example of a reconstructed 3D volume of the scanned region of a test specimen. Based on such 3D volumes, 2D slices in any desired plane can be made. Figure 3a shows an internal slice in the $x, y$-plane of a test specimen in the unloaded state. From this figure it can be seen that the flax fibres are situated in large semi-circular fibre assemblies with diameters of 300-400 $\mu \mathrm{m}$. These fibre assemblies are the flax yarns. A number of additional microstructural features can be seen on the tomograph including (i) the flax fibres having polygonal cross-sectional shapes and variable sized luminal cavities, (ii) the unseparated bundles of fibres within the yarns, (iii) the PP matrix which is impregnating the fibre yarns almost completely, (iv) the different types of porosities located inside the fibres, at the fibre/matrix interfaces, and in the matrix, and (v) the cracks, located especially in proximity to the surfaces of the specimen. As the specimen is in the unloaded state, these cracks must be a result of specimen preparation.

Figure $3 \mathrm{~b}$ shows a slice of the same specimen as in Figure $3 \mathrm{a}$, but now in the $x, z$-plane. It is seen that the flax fibre yarns are now parallel to the $z$-axis, while the individual fibres are observed to be oriented with an angle to the yarn axis of about $10-15^{\circ}$. This is expected since natural fibre yarns are made by a 
spinning process where the fibres are twisted in a helical configuration. Note that this angle is smaller than the surface twisting angle $\left(18^{\circ}\right)$, indicating that the fibre twisting angle is not constant through the yarn [13].

\subsection{Microstructural damage}

Having established that a number of microstructural features can clearly be observed from the tomographs, the following sections will focus on how damage develops in the specimens during uniaxial loading in the fibre yarn direction. The five specimens that were tested by the step-wise loading during XTM scanning showed an average failure stress of $109 \pm 8$ MPa. By having carefully inspected all reconstructed 3D volumes, it is evident that three characteristic damage mechanisms can be identified: (i) interface splitting cracks, (ii) matrix shear cracks, and (iii) fibre failures. A single test specimen has been chosen, and representative 2D slices at different stress levels will be shown to visualize and describe the three damage mechanisms. The chosen test specimen is assumed to be representative, and was selected because it contained the fewest number of initial defects from specimen preparation and handling.

\subsubsection{Interface splitting cracks}

Fiber/matrix-interface debonding was found to be a dominating damage mechanism in all analyzed specimens. At high load levels, these debondings resulted in large (around 0.5-1.0 mm) splitting cracks, i.e. cracks oriented along the fibres in the $z$-direction, propagating along the interfaces between the fibres and matrix. Accordingly, this damage mechanism is denoted interface splitting cracks. Examples can be seen in Figure 4 and Figure 5. 
Figure 4 shows a 2D slice in the $x, z$-plane, $140 \mu \mathrm{m}$ from the middle of the specimen. The figure exemplifies how the splitting cracks typically initiate at the notch and grow in the $z$-direction when the load is increased. The individual splitting cracks are indicated with numbers on the images. On the image showing the $20 \mathrm{MPa}$ stress level, splitting cracks 1 and 2 are seen. These cracks are also present at the unloaded state (image not shown here) and therefore cracks 1 and 2 are believed to result from specimen preparation. At $60 \mathrm{MPa}$, it is observed that the openings of cracks 1 and 2 have increased. Furthermore, two additional splitting cracks 3 and 4 are now observed. At $90 \mathrm{MPa}$, crack 2 has merged with crack 1, thereby forming one large crack. Cracks 3 and 4 are now longer and have larger crack openings. As also indicated in the images, the location of the crack tip is moving downwards, demonstrating that the splitting crack length increases with increasing applied stress. At the final stress level of $110 \mathrm{MPa}$, the combined crack 1-2 has a crack opening of around $20 \mu \mathrm{m}$. Cracks 3 and 4 have merged to form a large crack with a crack opening of around $15 \mu \mathrm{m}$. Moreover, an additional crack 5 has appeared and the combined length of the splitting crack (cracks 1-5) is now about $700 \mu \mathrm{m}$. The specimen failed when the stress level was increased above $110 \mathrm{MPa}$.

Figure 5 shows an $x, y$-slice positioned $458 \mu \mathrm{m}$ above the middle of the specimen. As indicated with arrows on the images, numerous smaller splitting cracks can be observed. The length and opening of these cracks is increased when the stress is increased. At the $110 \mathrm{MPa}$ stress level, a dotted line on the image shows the projected position in the $z$-direction of the centre of the left notch. It is seen that the majority of splitting cracks are found around the dotted line, indicating that they initiate at the centre of the notch, and then propagate in the $z$-direction. In addition, close inspection of Figure 5 reveals that a significant amount of the interface splitting cracks is formed at the interfaces of bundles of unseparated 
fibres. This is shown in more detail in Figure 6, where it is clearly seen that splitting cracks initiate at the fibre bundles.

In most cases, the interface splitting cracks are found to develop at the $60 \mathrm{MPa}$ stress level, and then grow at each following load step.

\subsubsection{Matrix shear cracks}

Shear cracks [17] were found to evolve in matrix rich regions of the composite, i.e. in the regions between the fibre yarns. Figure 7 shows examples of matrix shear cracks in a 2D slice in the $x, z$-plane, $270 \mu \mathrm{m}$ from the middle of the specimen. As indicated in the figure, initiation of matrix shear cracks is seen at positions $\mathrm{A}$ and $\mathrm{B}$ at $90 \mathrm{MPa}$ stress, and at position $\mathrm{C}$ at $100 \mathrm{MPa}$ stress. All observed matrix shear cracks grow with increasing load. Moreover, it was found that in regions with no fibres nearby, the shear cracks evolved along an almost straight line, as seen at position C. By investigating the region around the shear crack in all directions, it was confirmed that no fibres were in close proximity to the shear crack at position C. In cases where the shear cracks evolve in matrix regions with nearby fibres, the cracks are found to deviate from the straight line, and instead propagate along the nearby fibre/matrix interface, as seen at positions A and B in Figure 7. A close-up of the position B matrix shear cracks at 6x magnification is shown in Figure 8. In general, it was found that matrix shear cracks initiate at the $90 \mathrm{MPa}$ stress level, and then grow at each following load step.

\subsubsection{Fibre failures}

Careful inspections of the obtained 3D volumes revealed a number of observations of individual fibres that failed at the highest stress level (110 MPa). Based on a 2D slice in the $x, z$-plane, $14 \mu \mathrm{m}$ from the middle of the specimen, Figure 9 shows several examples of such fibre failures at $110 \mathrm{MPa}$. The figure shows also the same $2 \mathrm{D}$ slice at $60 \mathrm{MPa}$, and this demonstrates that the fibres in most cases fail exactly 
where initial structural irregularities can be seen in the fibres. These structural irregularities are classified as defects.

An example of a fibre failure at a barrel-shaped defect is seen in Figure 10. The $x$-coordinate of the $y, z$ slices in Figure 10a-b has been chosen such that the surface of the fibre is visualized. Thereby, the external shape of the defect is visible. The slices shown in Figure 10c-d are positioned $4.1 \mu \mathrm{m}$ behind the slices in Figure 10a-b. This means that these slices go through the centre of the fibre, showing the lumen and the internal shape of the same defect. It is seen that the fibre fails exactly at the defect.

Figure 11 shows failure of a fibre bundle resulting in a fibre failure region which is about $60 \mu \mathrm{m}$ wide. Again, defects can be seen on the fibres prior to fibre failure as exemplified in the $35 \mathrm{MPa}$ stress level image.

All fibre failures in Figure 9, Figure 10 and Figure 11 occur as the specimen is loaded to a nominal stress of $110 \mathrm{MPa}$, which is the final load step before ultimate failure.

\subsubsection{Overview of damage mechanisms}

Figure 12 shows a schematic load-displacement curve along with sketches of the three observed damage mechanisms. The figure summarizes the findings of the typical locations and stress levels for the three damage mechanisms: (i) interface splitting cracks originate near the surface of the notch region at a low stress level of $60 \mathrm{MPa}(\sim 50 \%$ of failure stress), (ii) matrix shear cracks originate at a medium stress level of $90 \mathrm{MPa}(\sim 75 \%$ of failure stress), and (iii) fibre failures originate at locations of fibre defects at a high stress level of $110 \mathrm{MPa}(\sim 90 \%$ of failure stress). 


\section{Discussion}

\subsection{Evaluation of the XTM testing approach}

The five specimens tested during XTM observation failed at $109 \pm 8 \mathrm{MPa}$. The two specimens tested in the laboratory with a standard tensile test machine operated at a comparable stepwise loading sequence failed at 111 and $140 \mathrm{MPa}$, while the two specimens tested in the laboratory in the monotonic tensile setup failed at 161 and $169 \mathrm{MPa}$. Small differences in geometry and fibre volume fractions between specimens are expected to give rise to a relatively large spread in the strength results. But the found strength reduction when testing in the stepwise fashion vs. the monotonic fashion (110-140 vs.160-170 $\mathrm{MPa}$ ) requires an explanation. It is assumed to be due to time-dependent deformations of the materials. In the monotonic test, a tensile test to failure took about 1 minute, while the stepwise loading procedure took more than 90 minutes in the laboratory, and more than four hours in the XTM facility, as a single scan took roughly 30 minutes. Even though the specimen was unloaded by $25 \%$ at each load step in order to avoid crack growth during scanning, load drops of 1-4\% were observed during each hold, which indicates that some relaxation occurred during holding. It is therefore assumed that the stepwise loading sequence gives rise to time-dependent deformations, which lowers the composite strength.

It was assumed that the X-ray beam did not alter or harm the specimen in any way. However, this was not experimentally validated. The influence of the beam on the specimen could be tested by exposing a number of specimens to the synchrotron X-ray beam in an unloaded state, and then test them in the laboratory. The measured strength values should be compared with the strength values of identical specimens that have not been exposed to X-rays. 
It was found that XTM is a very strong technique for investigating 3D structures with high resolution. However, to achieve the desired resolution, the field of view was restricted to $1.48 \times 1.48 \times 1.48 \mathrm{~mm}^{3}$. An inherent feature for natural fibre composites is variations in fibre thickness, yarn thickness, twisting angles etc. [13]. In spite of this variability, the five samples investigated, displayed the same failure mechanisms and therefore the results are assumed to be representative. And even though the field of view is small, the $3 \mathrm{D}$ nature of the XTM technique is a clear advantage compared to the 2D nature of the traditional cross-sectional microscopy technique.

\subsection{Interface splitting cracks}

As exemplified in Figure 6, a large amount of interface splitting cracks appeared at fibre bundles, especially near the edges of the specimen. This demonstrates that the interfaces between these relatively large fibre bundles and the matrix are particularly susceptible to cracks. Thus, it seems that the fibre bundles act as stress concentrators at the microscale.

Generally, an interface splitting crack at the atomic level involves breaking the (chemical, electrostatic and/or mechanical) bonds constituting the interface, and this requires energy. Thus, the development of an interface splitting crack consumes a certain amount of energy per unit area of new fibre/matrixinterface surface area generated by the crack. This amount of energy is a material property called the critical energy release rate or the fracture energy $G_{\mathrm{c}}$. However, when a splitting crack is propagating, an amount of potential energy per unit area of new fibre/matrix-interface surface area is released, denoted the energy release rate $G$. Under displacement-controlled tensile loading, this energy comes from release of elastic energy stored in the specimen during loading, some of which is released during 
splitting, as the specimen complies with the external load. Splitting cracks can propagate when the energy release rate $G$, equals or exceeds the critical fracture energy $G_{\mathrm{C}}$,

$$
G \geq G_{\text {c. }}
$$

The fracture energy $G_{\mathrm{c}}$ is a material (interface) property, whereas the energy release rate $G$ depends on load level and geometry. In the case of interface splitting cracks, the energy release rate $G$ depends linearly on the fibre radius [18],

$$
G=1 / 4 \cdot \varepsilon_{f}^{2} \cdot E_{f} \cdot r,
$$

where $\varepsilon_{f}$ and $E_{f}$ are the strain and Young's modulus of the fibre, respectively, and $r$ is the radius of the fibre, which is simplified to have a circular cross-section. Equation 2 is derived from an analysis of fibre pullout, but it is believed that it can be applied in the present case as well. A similar functional relationship is found for an analysis of a splitting crack from a central flaw [19]. As the energy release rate $G$ is proportional to the fibre radius $r$, Equation 2 implies that a fibre bundle, idealized as a very large circular fibre, needs a lower strain for Equation 1 to be fulfilled. Thus, interface splitting is more likely to develop at the thick fibre bundles than at the thin individual fibres.

The XTM observations (Figure 5 and Figure 6) and the above model-based argumentation underline the importance of achieving a high degree of separation of the originally large flax fibre bundles into individual fibres, in order to limit the development of interface splitting cracks. 
In general, interface failures are a concern for all composite materials. It is, however, a special concern for natural fibre composites, as natural fibres have a complex hydrophilic surface chemistry, which complicates fibre/matrix bonding in the case of thermoplastic matrix polymers, since these are often hydrophobic. Attempts are being made to make the fibres less hydrophilic, by using various chemical treatments [20].

A point to investigate in future studies is the influence of fibre twisting on the damage mechanisms. In the present study, it was found that the composites were susceptible to interface debonding. Therefore, one might speculate that especially the splitting cracks might be affected by alterations in the microstructure of the material, e.g. due to fibre twisting.

\subsection{Matrix shear cracks}

It was found that the path of matrix shear cracks are highly influenced by the presence of fibre/matrix interfaces. The observation that the shear cracks are following these interfaces underlines the tendency of the interfaces to undergo debonding. It also shows how the composite microstructure influences the evolution of the microscale damage.

The matrix shear cracks are not observed to cause fibre breaks. Instead they grow along the fibre/matrix interfaces, as shown in Figure 7. When a matrix shear crack grows towards a fibre yarn, the crack is assumed to deviate from its original trajectory and instead grow along the yarn in the $z$ direction, as an interface splitting crack. Therefore, matrix shear cracks are not believed to be critical with respect to ultimate failure. In order to investigate this assumption in future studies, it would be 
advantageous to scan the two pieces of a broken specimen by XTM. In this way, it would be possible to establish whether the ultimate failure crack grows via the matrix shear cracks.

\subsection{Fibre failures}

The majority of the fibre failures were found to occur at locations where the fibres had visible structural irregularities. Such irregularities are believed to be defects in the cell wall of the fibres, such as kink bands or barrel-shaped nodes. The same behaviour has previously been observed in single fibre tests [21].

Figure 13a shows a scanning electron micrograph of a kink band on the flax fibres. Figure 9 demonstrates how such kink bands result in fibre failure at the final load step. The kink bands are defects, believed to result from handling and processing of the fibres resulting in a disordered arrangement of the cellulose microfibrils in the cell wall [7].

Figure $13 \mathrm{~b}$ shows a scanning electron micrograph of a node on a flax fibre with a barrel-shaped bulging appearance. Figure 10 shows an example of a fibre which has failed at such a barrel-shaped node.

Figure 10c shows that the node is also bulging on the inside of the fibre lumen. Due to the symmetric appearance of this kind of feature, the barrel-shaped nodes are speculated to be developed naturally in the fibres during their growth. Within the observed composite specimens, several fibres are observed to fail at such barrel-shaped nodes. Even though they might be naturally occurring, they must be regarded as defects nonetheless, when the fibres are used for composite reinforcement. 
Figure 11 shows an example of a fibre bundle with a large-scale defect across the bundle, similar to what is seen on the micrograph in Figure 14. It appears that all fibres in the bundle fail simultaneously, implying that the bundle effectively behaves as a single large fibre. When such a fibre bundle fails, the load carried by the fibre bundle will be distributed to the surrounding region of the composite material. Thus, a fibre bundle failure gives rise to a large stress concentration at the microscale. It can therefore be concluded that failure of fibre bundles are more critical than failure of individual fibres where a number of smaller stress concentrations occur. This conclusion is in agreement with the findings from studies of fibre-fibre interactions and local load sharing, where it is found that the stress concentration resulting from a fibre break is largest near the fibre [22-24], and that the magnitude of the stress concentration factor increases with the number of broken fibres in a cluster [22-24].

\subsection{Fibre separation}

The findings in the present study suggest that an improved separation of fibre bundles into individual fibres will have a positive influence on the composite damage behaviour. The separation of fibre bundles can be achieved by degrading the pectin molecules cementing the individual fibres together in the raw flax fibres. Various approaches can be used to degrade the pectin molecules. An enzymatic treatment with pectinase can be used to break bonds in the cementing pectin molecules of the middle lamella between individual fibres [4]. A chemical treatment with ethylenediaminetetraacetic acid (EDTA) can be used to remove $\mathrm{Ca}^{2+}$-ions which stabilize the pectin molecules. Both treatments have the desired effect of separating the fibres. However, in general, all treatments designed to separate fibre bundles into individual fibres are found to have a negative influence on the single fibre strength properties [4]. Specifically, it is known that various chemical treatments cause fibre strength reductions 
due to an increase in size and numbers of fibre defects [8]. Furthermore, it has been found that the density of fibre defects increases with the number of fibre processing steps [25].

Altogether, based on the findings in the present study and in previous studies, it is suggested that a balance should be found between the following two scenarios:

1. A low degree of separation treatment gives a high number of fibre bundles in the composite. Thus, a higher number of splitting cracks is likely to occur at these large-radius bundles. As a result of the mild treatment, the density and severity of kink bands will be lower. However, the fibre bundles are susceptible to large-scale defects across the bundle (see example in Figure 14), possibly arising from the bundle being excessively bent during processing of the fibres. This means that while the overall density of kink bands leading to failure of individual fibres will be lower, there will be a high amount of failures of large fibre bundle. When all the fibres of a fibre bundle fail simultaneously, as seen in Figure 11, a large stress concentration develops at the microscale. This could possibly cause failure of neighbouring fibres eventually leading to ultimate failure.

2. A high degree of separation treatment gives a low number of fibre bundles in the composite, but also a high number of fibre defects. The high degree of separation into small-radius fibres will restrict the development of splitting cracks, while the larger number of fibre defects will lead to a larger number of fibre failures. However, due to the good separation, the locations of these fibre failures will be homogenously distribution in the composite in all three directions, meaning that they do not give rise to large stress concentrations. Thereby the composite will be able to sustain a higher number of fibre failures before ultimate failure occurs. 
It has been found that EDTA treatment is superior to enzymatic treatment, as it gives higher strength properties of natural fibre composites [4]. The stiffness of the composites was found to be largely independent of the type of fibre treatment. The composite strength, however, shows a relatively large dependency on fibre treatment, with the well separated EDTA-treated fibres giving composites with $50 \%$ higher strength in comparison with the untreated fibres. These findings support the suggestion in the present study that improved separation of fibre bundles is a key parameter to obtain stronger composites.

\subsection{Damage mechanisms leading to ultimate failure}

While matrix shear cracks are not believed to be critical for composite failure, it is not trivial whether interface splitting cracks or fibre failures is the most critical mechanism of damage. Whereas a large amount of splitting was observed to occur during a number of load steps before failure, fibre failures were only observed to occur in the last load step, which indicates that fibre failure could be the critical mechanism. On the other hand, it is evident that fibre failures must take place before specimen failure. But this does not prove that fibre failure is the critical damage mechanism. However, the vast majority of the applied load supported in a composite specimen is carried by the reinforcing fibres. Thus, assuming a local load sharing mechanism [23], the failure of individual fibres means that the surrounding fibres have to carry more load, making them more vulnerable to breaking themselves. Thus, it seems reasonable to conclude that fibre failures is the most critical damage mechanism, and that attempts should be made to avoid especially the large fibre bundle failures.

As mentioned, the specimens were notched to ensure damage initialization in the volume visualized with the XTM technique. The matrix shear cracks are believed to be a direct consequence of the chosen 
specimen geometry. The splitting cracks are mainly seen to emanate from the notches and specimen surfaces. Thus, they are also strongly related to the chosen specimen geometry. Therefore the damage mechanisms in a larger straight edge specimen are likely to differ from the results of the present work.

\section{Summary and conclusions}

In the present study, unidirectional flax fibre composite specimens were tested by uniaxial loading in the fibre yarn direction. During testing, in situ X-ray tomographic microscopy (XTM) observations were made using synchrotron radiation. A notched sample geometry were used in order to ensure damage initialization in the volume visualized with the XTM technique. Three distinct damage mechanisms were observed: (i) interface splitting cracks typically seen at the interfaces of bundles of unseparated fibres, (ii) matrix shear cracks, and (iii) fibre failures typically seen at fibre defects. The three damage mechanisms initiated at about 50,75 and $90 \%$ of the failure stress respectively.

The matrix shear cracks are believed to have a minor influence on the actual specimen failure. Interface splitting cracks is visually the most dominating defect mechanism. It is, however, argued that the observed fibre failures was actually the most critical damage mechanism, as the fibres carry the vast majority of the load.

A characteristic feature of the investigated flax fibre composite is the presence of unseparated fibres bundles. These fibre bundles were found to play a significant role for the evolution of damage: It was found that fibre failures can happen simultaneously for all fibres in a fibre bundle, implying that the bundles effectively behave as very thick fibres. Large processing defects across the entire bundle are believed to account for this behaviour. When a bundle fails, a large amount of stress is transferred to 
the neighbouring matrix and fibres, making them likely to fail as well. It is therefore concluded that fibre bundles should be avoided, even if it involves using slightly harsher fibre separation treatments. When the fibres are completely separated, the fibre defects are distributed more homogenously in all three material directions. This is believed to result in stronger natural fibre composites. This hypothesis is in agreement with previous experimental studies. Based on the current study it is clear that the ideal natural fibre reinforcement is individual fibres which are evenly distributed in the composite. Therefore, also the traditional approach of locking the natural fibres in fibre yarns should be reconsidered.

\section{Acknowledgements}

The authors would like to thank the group of Professor Ian Sinclair at University of Southampton for providing the tensile testing fixture. We would like to thank the staff at the TOMCAT beamline for technical assistance and the PSI for granting us beam time. At Risø DTU, we would like to thank Christian H. Madsen for assistance with specimen preparation and Erik Vogeley for assistance with the testing routine. The research leading to these results has received funding from the European Comunity's Seventh Framework Programme (FP7/2007-2013) under grant agreement no 214467 (NATEX).

\section{References}

1. Baillie C (Ed). Green Composites: Polymer composites and the environment. Cambridge, 2009.

2. Lilholt H, Lawther JM. Natural organic fibres. In: Kelly A, Zweben C (Ed). Comprehensive composite materials (6 vols.), vol 1. Elsevier Science; 2000. 303-325 [Chapter 10]. 
3. Aslan M, Chinga-Carrasco G, Sørensen BF, Madsen B. Strength variability of single flax fibres. J Mater Sci 2011;46:6344-6354.

4. Stuart T, Liu Q, Hughes M, McCall RD, Sharma HSS, Norton A. Structural biocomposites from flax - Part I: Effect of bio-technical fibre modification on composite properties. Compos Part A 2006;37:393-404.

5. Andersons J, Joffe R, Hojo M, Ochiai. Glass fibre strength distribution determined by common experimental methods. Compos Sci Technol 2002;62:131-145.

6. Hughes M, Carpenter J, Hill C. Deformation and fracture behavior of flax fibre reinforced thermosetting polymer matrix composites. J Mater Sci 2007;42:2499-2511.

7. Bos HL, Molenveld K, Teunissen W, van Wingerde AM, van Delft DRV. Compressive behaviour of unidirectional flax fibre reinforced composites. J Mater Sci 2004;39:2159-2168.

8. Thygesen LG, Bilde-Sørensen JB, Hoffmeyer P. Visualisation of dislocations in hemp fibres: A comparison between scanning electron microscopy (SEM) and polarized light microscopy (PLM). Ind Crops Prod 2006;24:181-185.

9. Dai D, Fan M. Characteristic and performance of elementary hemp fibre. Mater Sci Appl 2010;1:336-342.

10. Hughes M, Hill CAS, Sèbe G, Hague J, Spear M, Mott L. An investigation into the effects of microcompressive defects on interphase behaviour in hemp-epoxy composites using half fringe photoelasticity. Compos Interfaces 2000;7(1):13-29.

11. Moffat AJ, Wright P, Buffière JY, Sinclair I, Spearing SM. Micromechanisms of damage in $0^{\circ}$ splits in a $[90 / 0]_{\mathrm{s}}$ composite material using synchrotron radiation computed tomography. Script Mater 2008;59:1043-1046. 
12. Wright P, Fu X, Sinclair I, Spearing SM. Ultra high resolution tomography of damage in notched carbon fiber epoxy composites. J compos mater 2008;42:1993-2002.

13. Madsen B, Hoffmeyer P, Thomsen AB, Lilholt H. Hemp yarn reinforced composites - I. Yarn characteristics. Compos Part A 2007;38:2194-2203.

14. Wright P, Moffat A, Sinclair I, Spearing SM. High resolution tomographic imaging and modeling of notch tip damage in a laminated composite. Compos Sci Technol 2010;70:14441452.

15. Groso A, Schneider P, Linga S, Mueller R, Abela R, Stampanoni M. Phase contrast tomography: an alternative approach. Appl Phys Lett 2006;88:214104.

16. http://www.vsg3d.com/avizo/overview

17. ZC Xia, JW Hutchinson. Mode II fracture toughness of a brittle adhesive layer. Int J Solids Struct 1994;31:1133-1148.

18. Tada H, Paris PC, Irwin GR. The stress analysis of cracks handbook. American Society of Mechanical Engineers, 2000.

19. Dollar A, Steif PS. The branched crack problem revisited. J Appl Mech 1991;58:584-586.

20. Zafeiropoulos NE, Williams DR, Baillie CA, Matthews FL. Engineering and characterisation of the interface in flax fibre/polypropylene composite materials. Part I. Development and investigation of surface treatments. Compos Part A 2002;33:1083-1093.

21. Baley C. Analysis of the flax fibres tensile behaviour and analysis of the tensile stiffness increase. Compos Part A 2002;33:939-948.

22. Wagner HD, Eitan A. Stress concentration factors in two-dimensional composites: effects of material and geometrical parameters. Compos Sci Technol 1993;46:353-362 . 
23. Van den Heuvel PWJ, Peijs T, Young RJ. Failure phenomena in two-dimensional multi-fibre microcomposites: 2. A Raman spectroscopic study of the influence of inter-fibre spacimen on stress concentrations. Compos Sci Technol 1997;57:899-911.

24. Fukuda H, Kawata K. On the stress concentration factor in fibrous composites. Fibre Sci Technol 1976;9:189-203.

25. Hänninen T, Thygesen A, Mehmood S, Madsen B, Hughes M. The effect of mechanical damage on the susceptibility of flax and hemp fibres to chemical degradation. In preparation. 


\section{Figure Captions}

Figure 1. Schematic illustration of the relation between a) fibre yarn, b) fibre bundle and c) individual fibres. Cross sections of the fibres are shown. The fibre yarn consists of individual fibres and fibre bundles. A fibre bundle consists of individual fibres bound together by pectin in the middle lamella. By applying chemical and mechanical treatments, the fibre bundles can be separated into individual fibres.

Figure 2. a) Sketch of a test specimen showing the specimen geometry. b) An example of a reconstructed 3D volume from the XTM scans. The volume corresponds to the box in a).

Figure 3. Examples of two internal 2D slices in a scanned 3D volume: a) slice in $x, y$-plane, and b) slice in $x, z$-plane. A number of microstructural features are indicated on the images.

Figure 4. Interface splitting cracks. Shown are four 2D slices at the same position in the $x, z$-plane, but at different stress levels. It is seen that the number and size of splitting cracks (indicated with numbers) grow with the applied stress. For the final stress level, the cracks grow together forming larger cracks.

Figure 5. Interface splitting cracks. The slice is positioned in the $x, y$-plane and represents different stress levels. Splitting cracks grow with increased applied stress. It is indicated that the fibre bundles consisting of 3-20 unseparated fibres are typical sites for initiation of interface splitting cracks. 
Figure 6. Close up of interface splitting cracks that initiates at fibre bundles. It can be noted that no splitting cracks are seen at individual fibres.

Figure 7. Matrix shear cracks. The evolution of the shear cracks is shown at different stress levels. It is seen that matrix shear cracking initiates at $90 \mathrm{MPa}$.

Figure 8. Matrix shear cracks. A close-up (6x magnification) of position B from Figure 7 showing the detailed evolution of matrix shear cracks at different stress levels.

Figure 9. Fibre failure. The fibres are observed to fail at positions where fibre defects can be seen initially.

Figure 10. Fibre failure at a barrel-shaped defect. Four slices in the $y, z$-plane. The images a) and b) show the unloaded and loaded states of a fibre with a barrel-shaped defect in a slice that is positioned such that it intersects the surface of the fibre. The images c) and d) show the same defect, but the slice is positioned $4.1 \mu \mathrm{m}$ further into the specimen in the $x$-direction, such that it intersects the middle of the fibre.

Figure 11. Fibre failures at a fibre bundle. The fibres all fail simultaneously in the same $x, y$-plane.

Figure 12. Schematic presentation of the characteristic damage mechanisms in natural fibre composites. In the present study, interface splitting cracks are found to initiate from the notches at $60 \mathrm{MPa}$. Matrix shear cracks initiate at $90 \mathrm{MPa}$. Fibre failures occur at $110 \mathrm{MPa}$, and are primarily seen at fibre defects. 
The given nominal stress values depend strongly on specimen geometry and fibre configuration, in addition to the properties of fibres, matrix, and interface.

Figure 13. SEM images of defects in flax yarn fibres: a) kink bands, and b) barrel-shaped nodes.

Figure 14. SEM image of a large defect across a flax fibre bundle. 
Figure 1

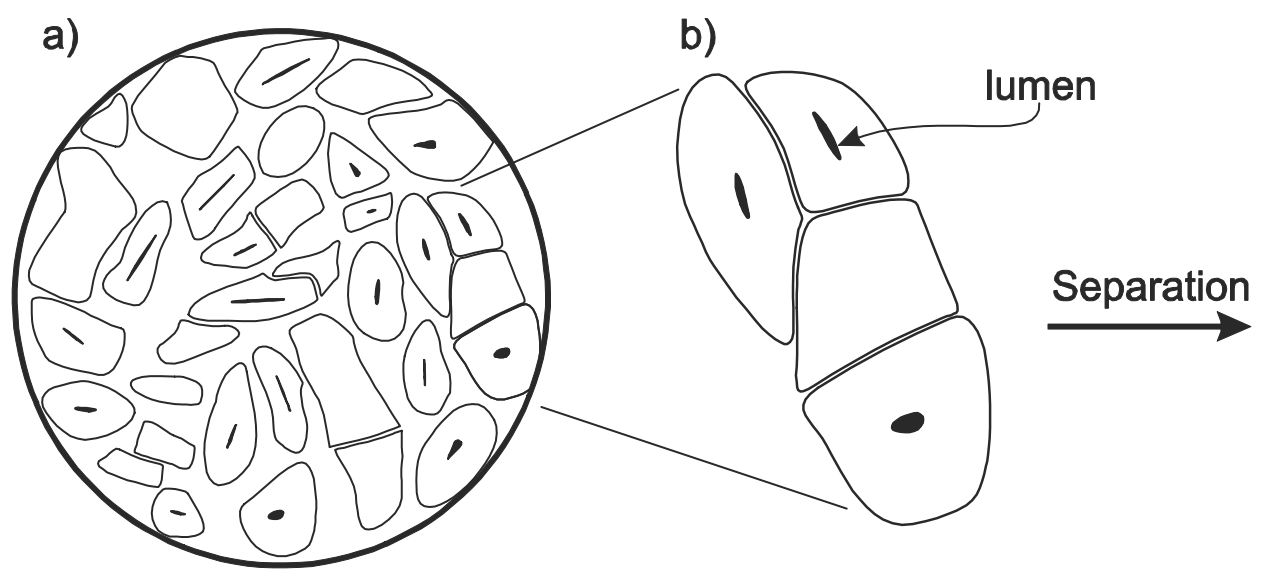

fibre yarn fibre bundle

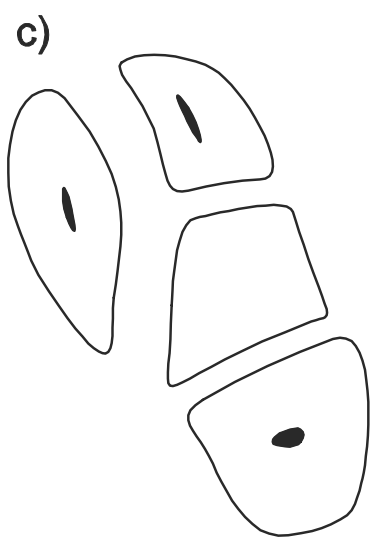

individual fibres 
Figure 2

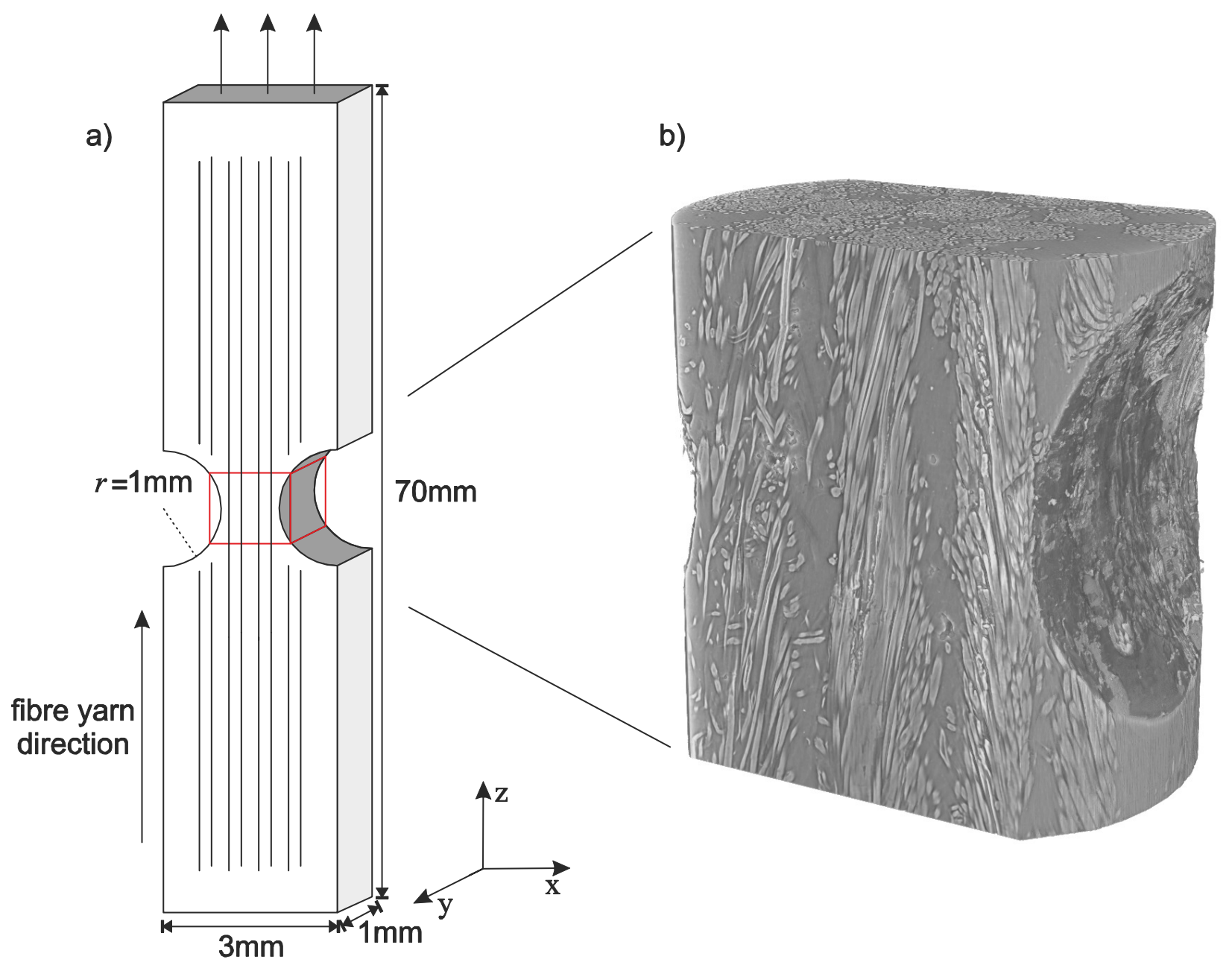


Figure 3
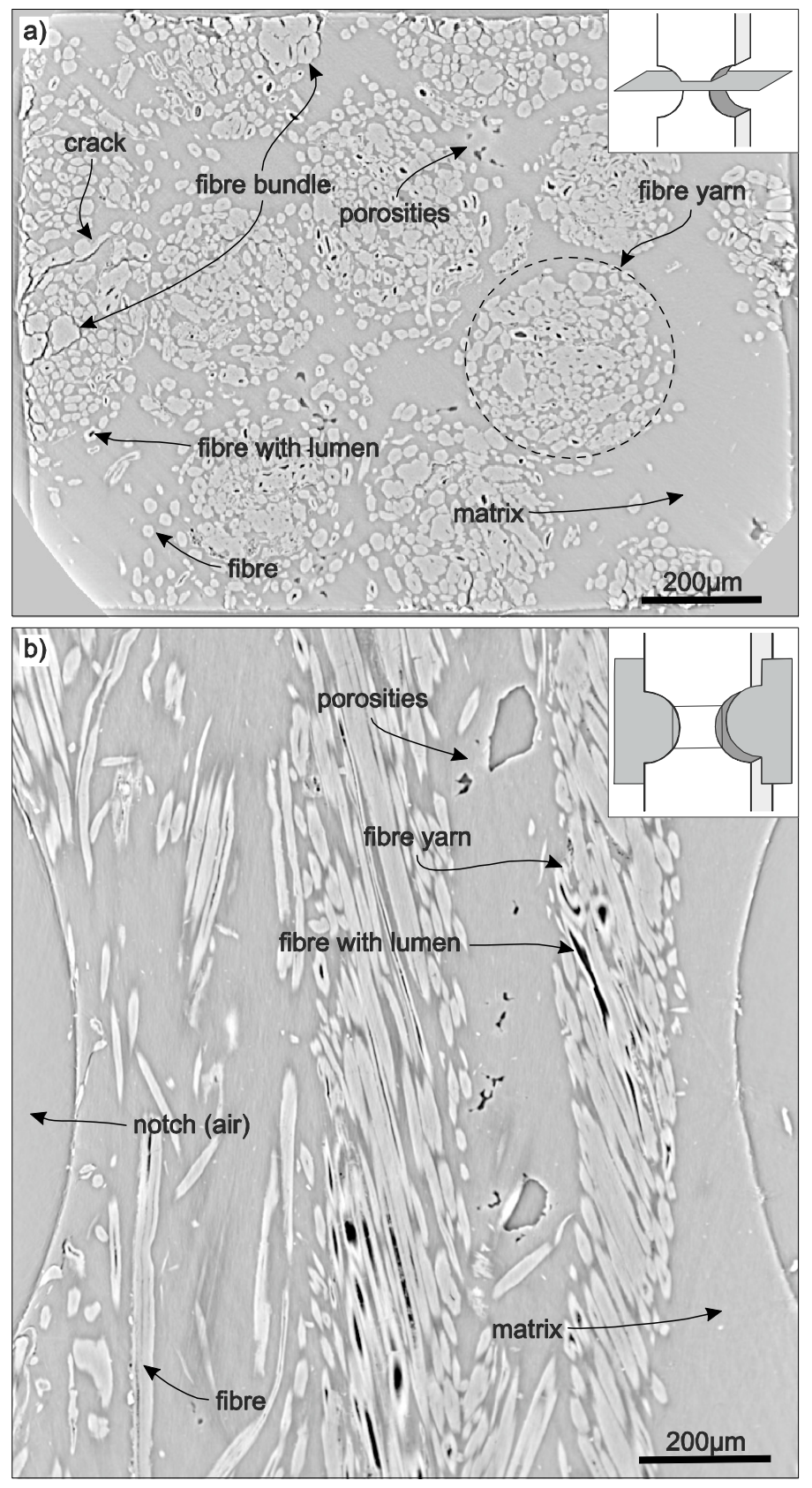
Figure 4

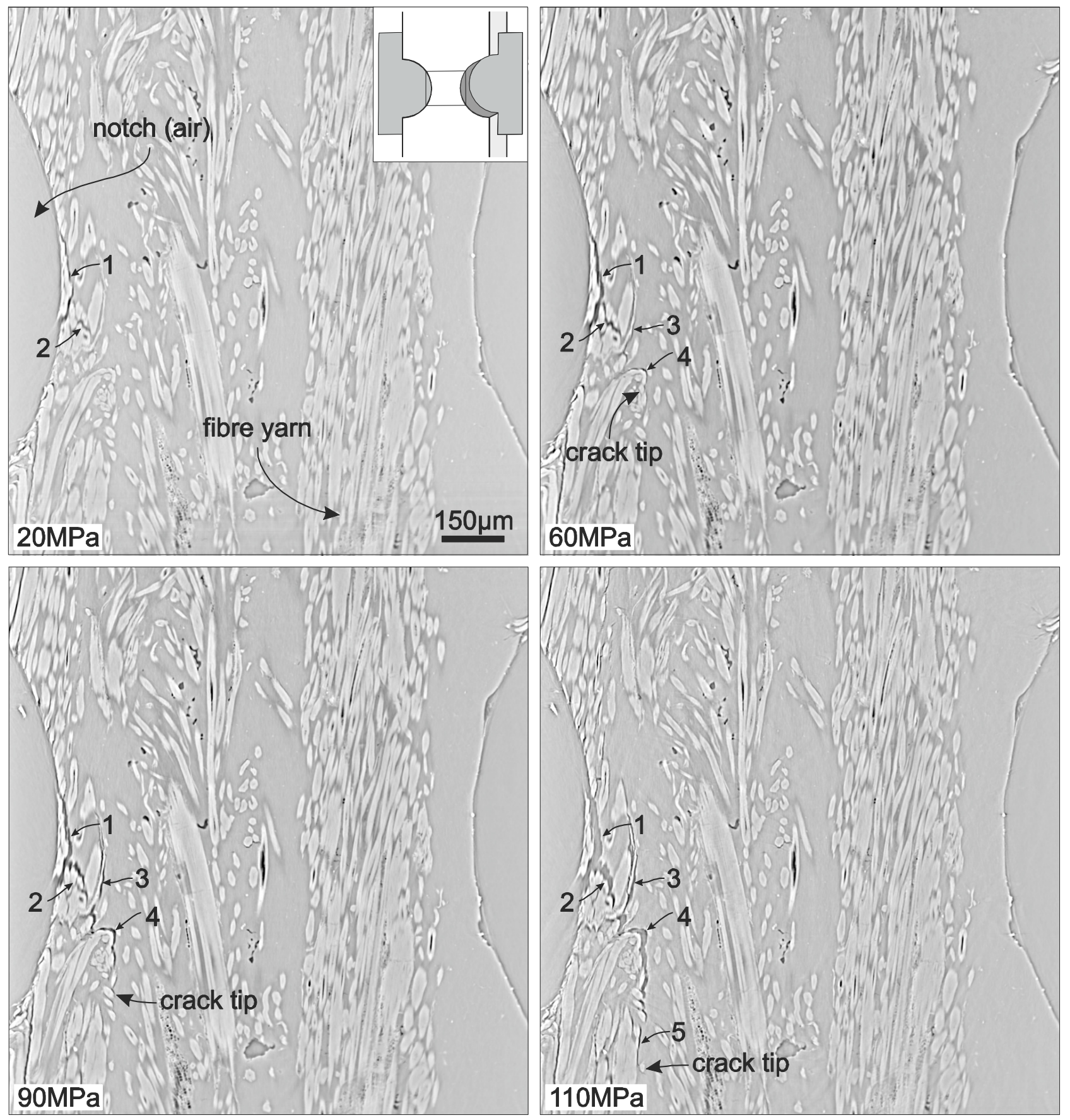


Figure 5
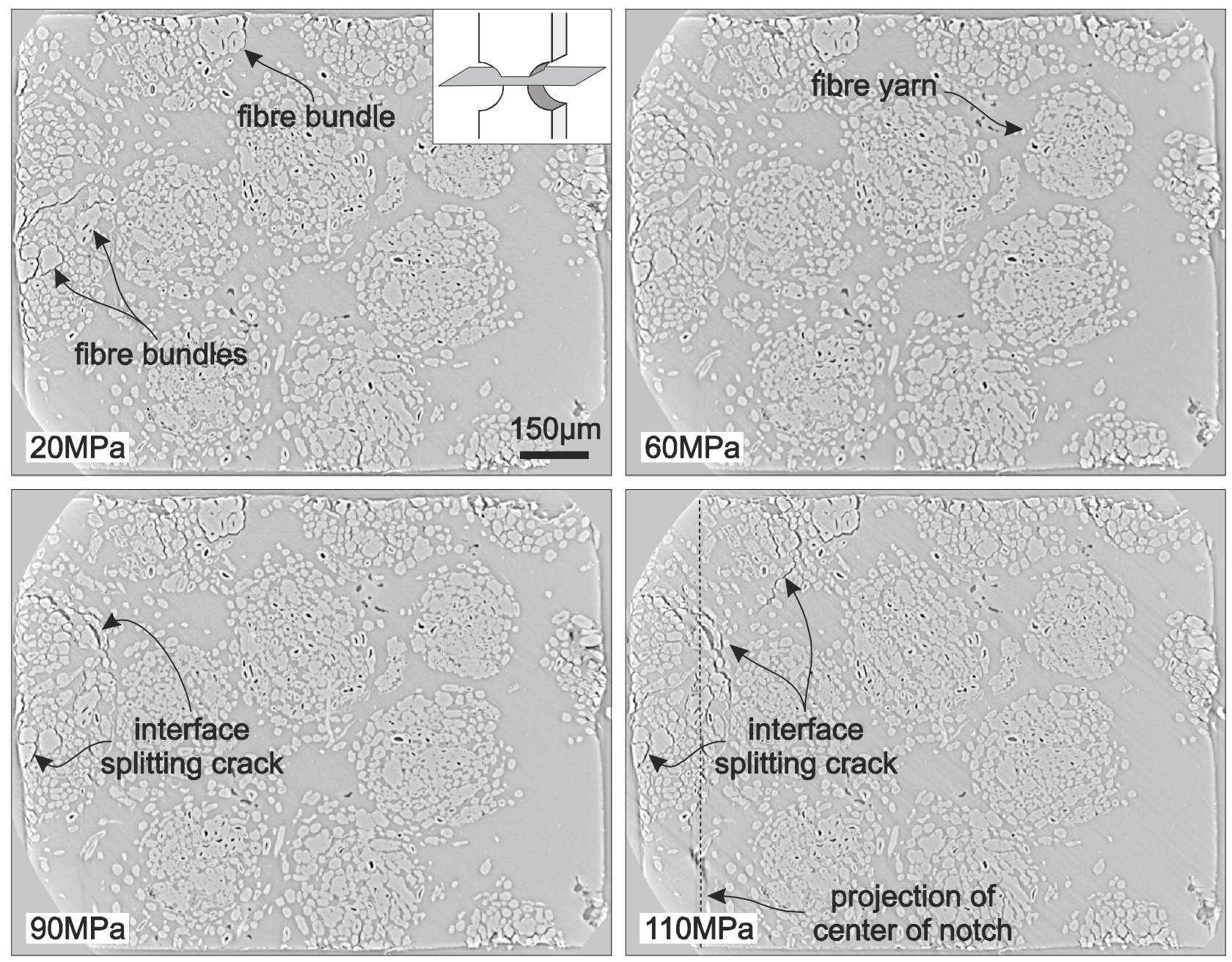
Figure 6

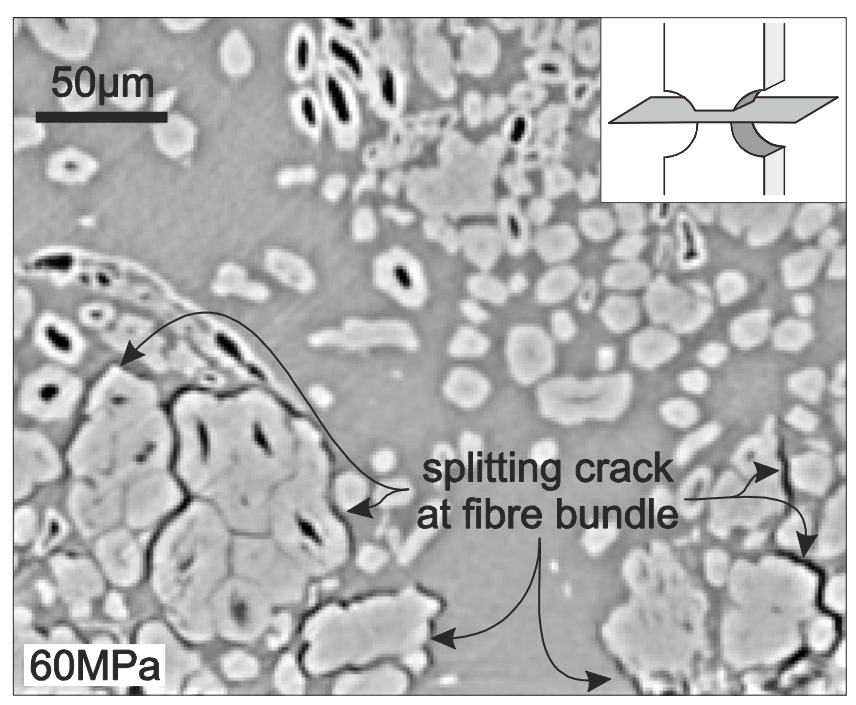


Figure 7
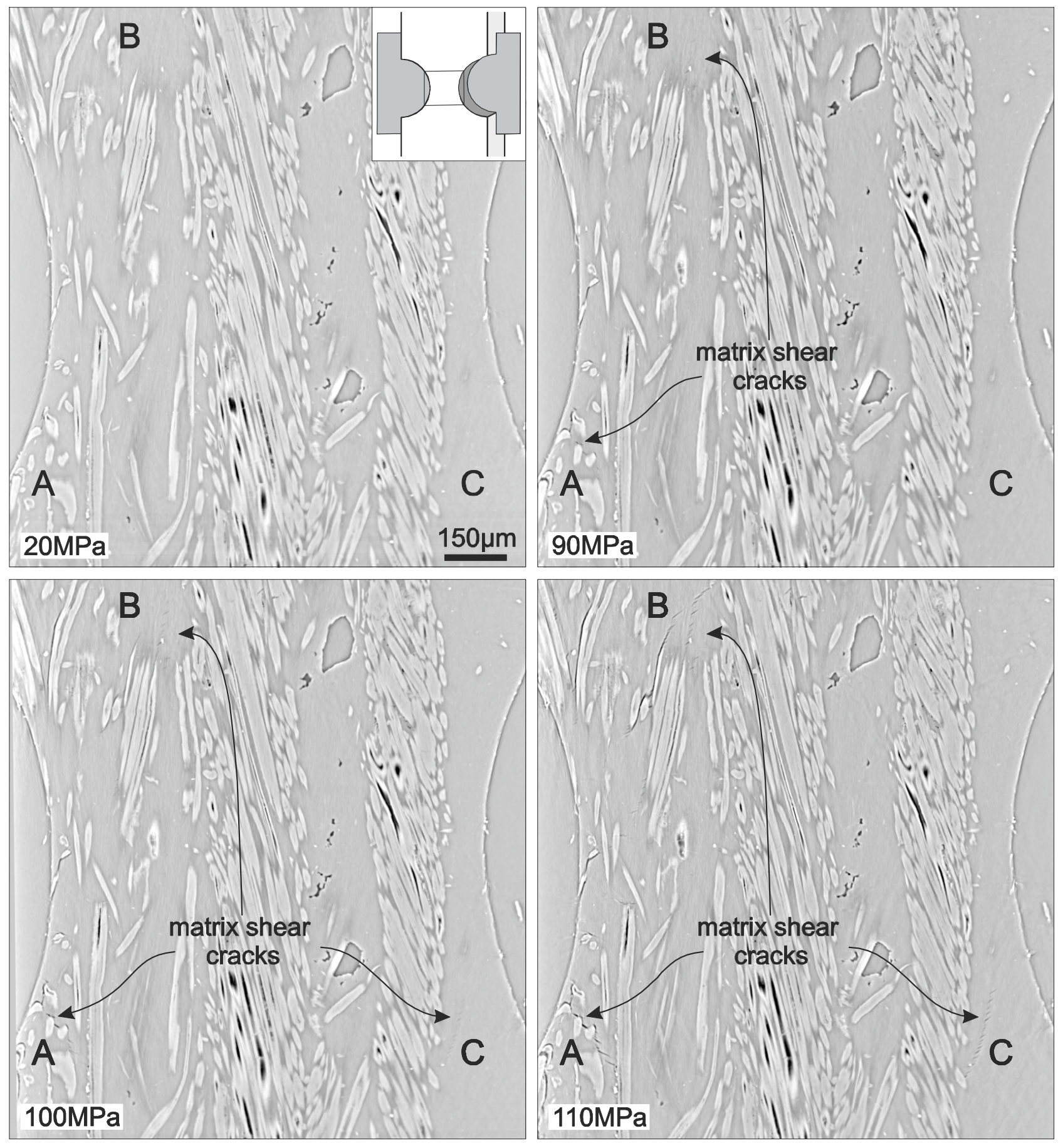
Figure 8
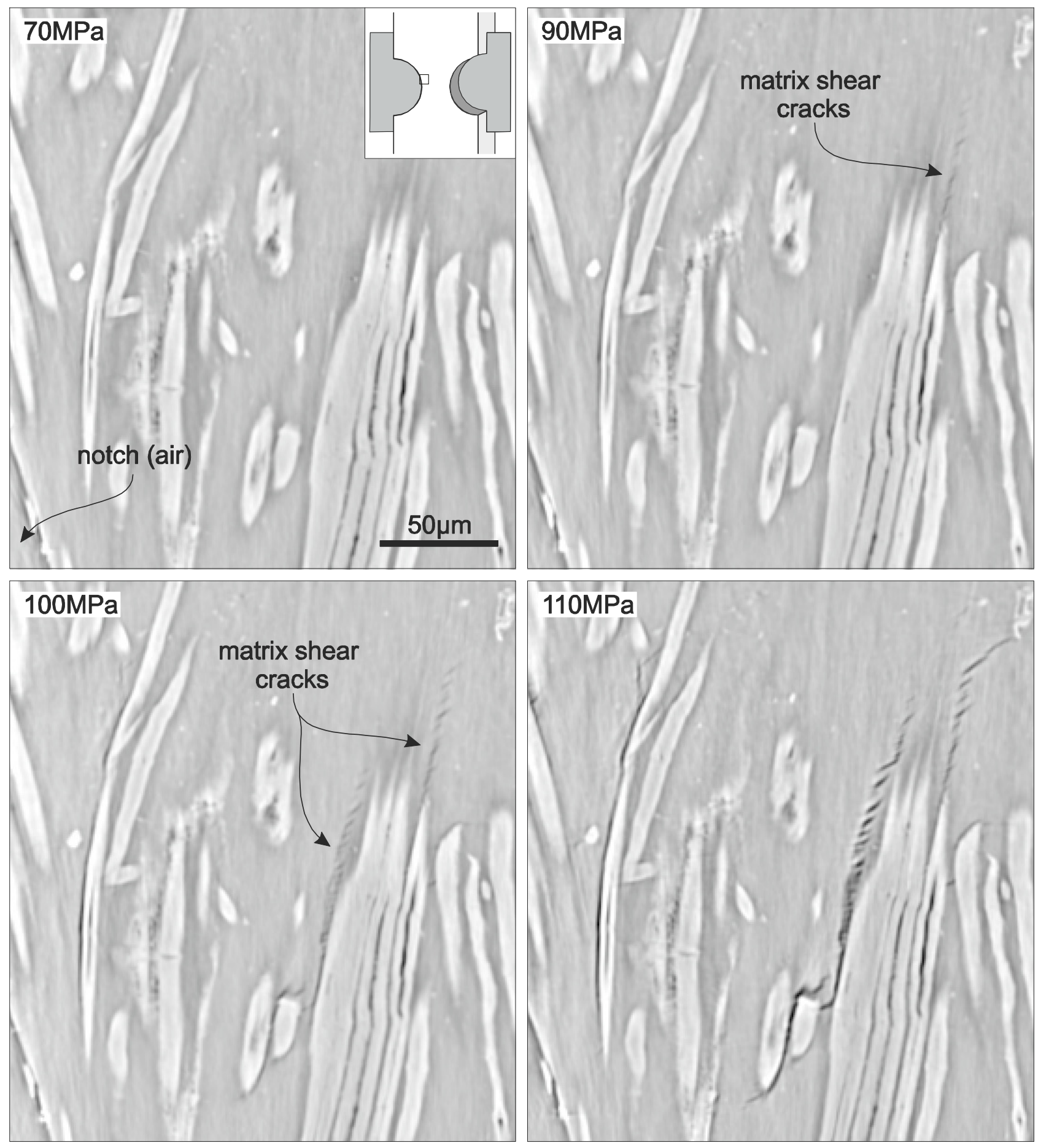
Figure 9
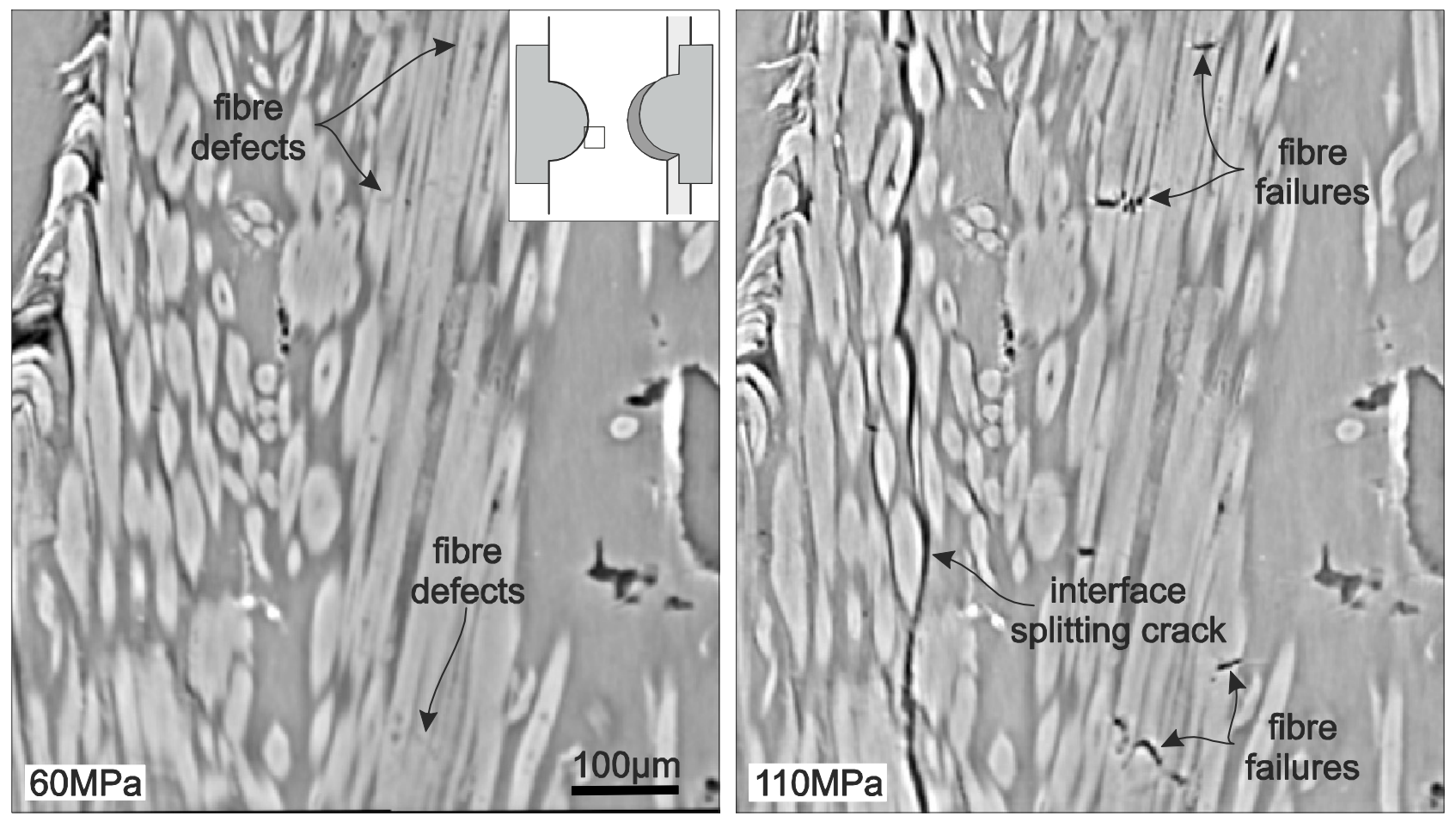
Figure 10
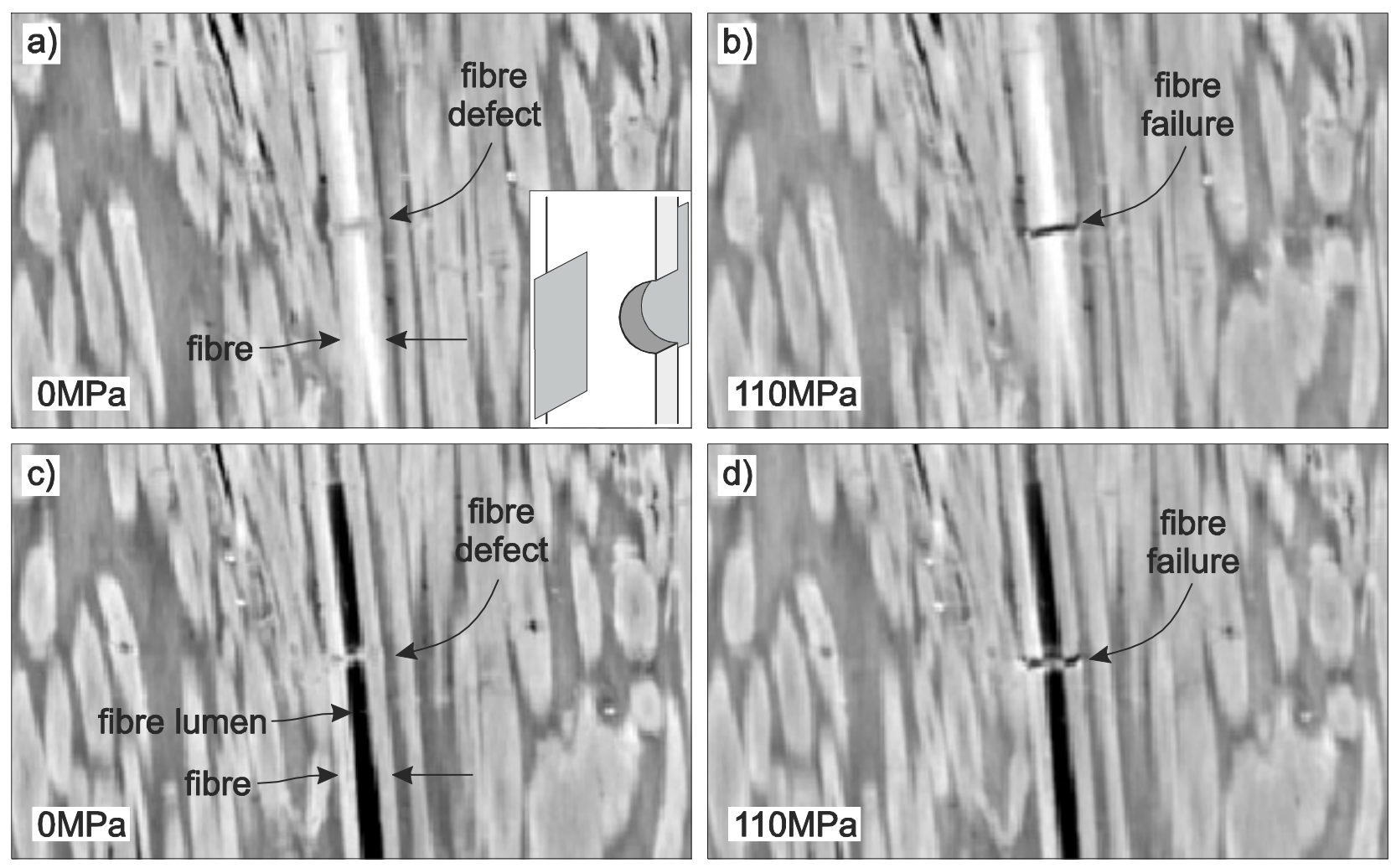
Figure 11
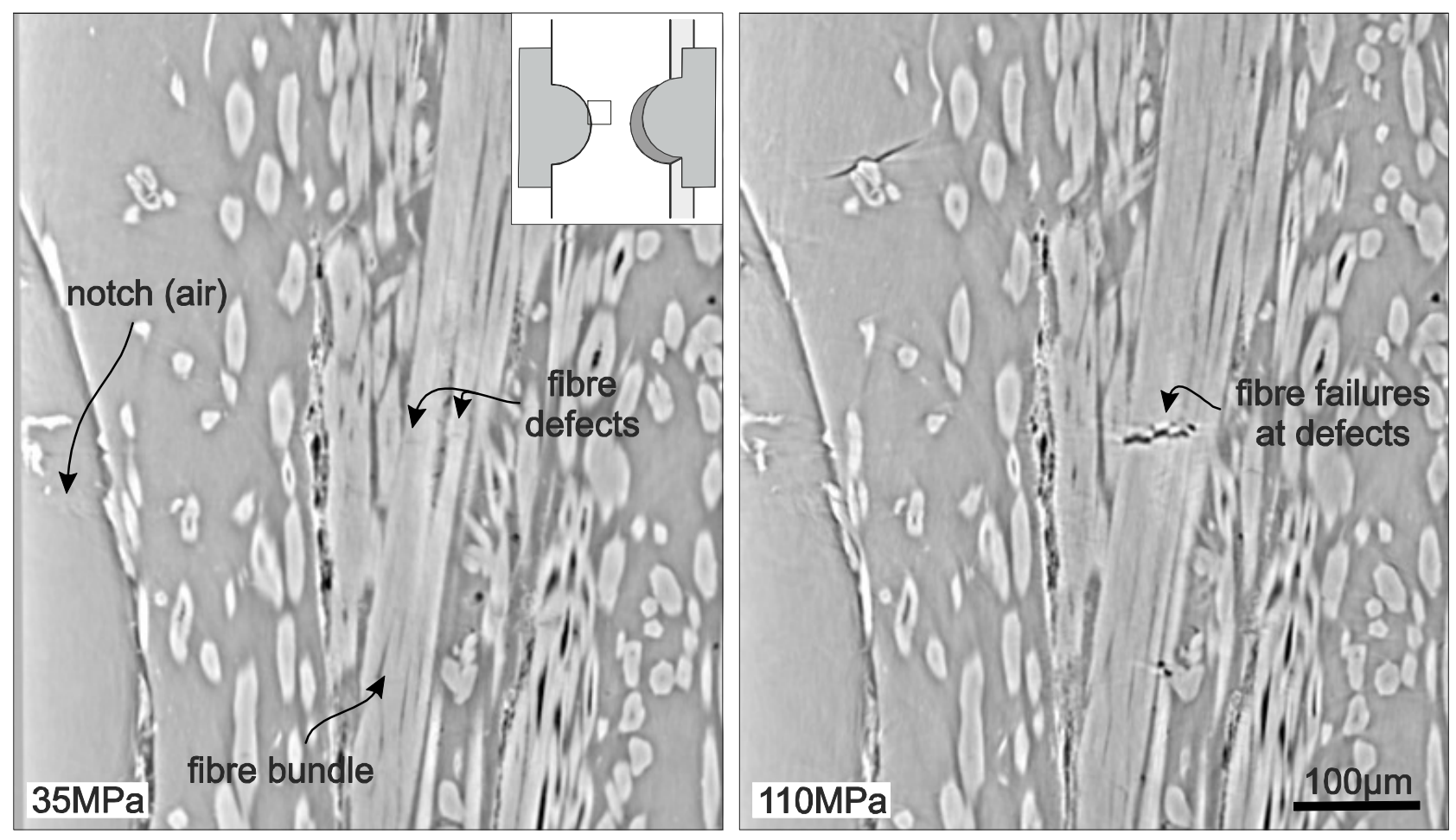
Figure 12
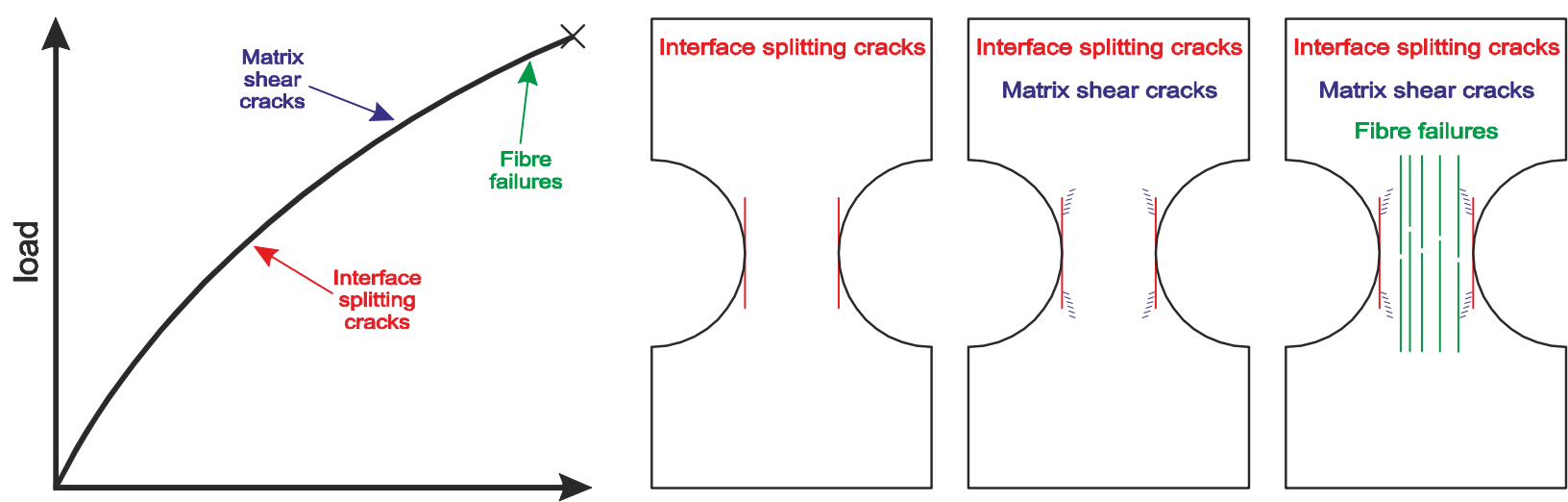

displacement 
Figure 13
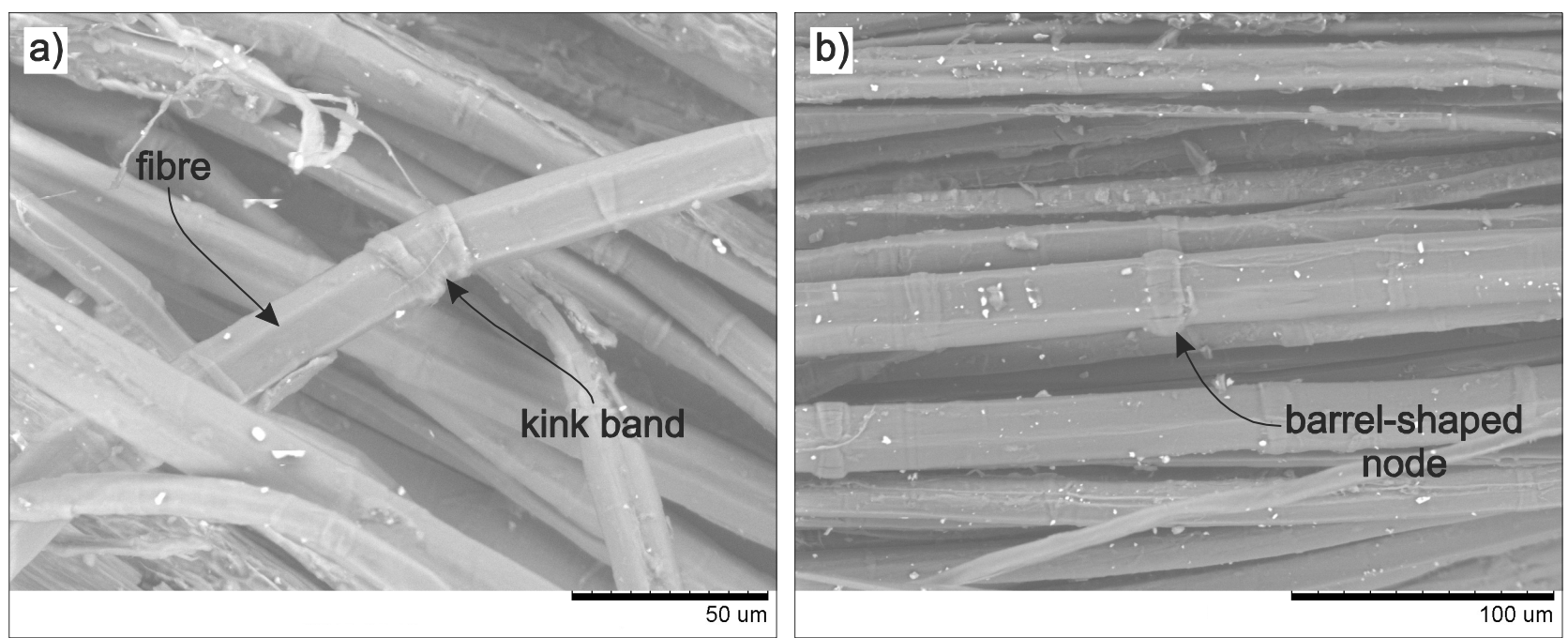
Figure 14

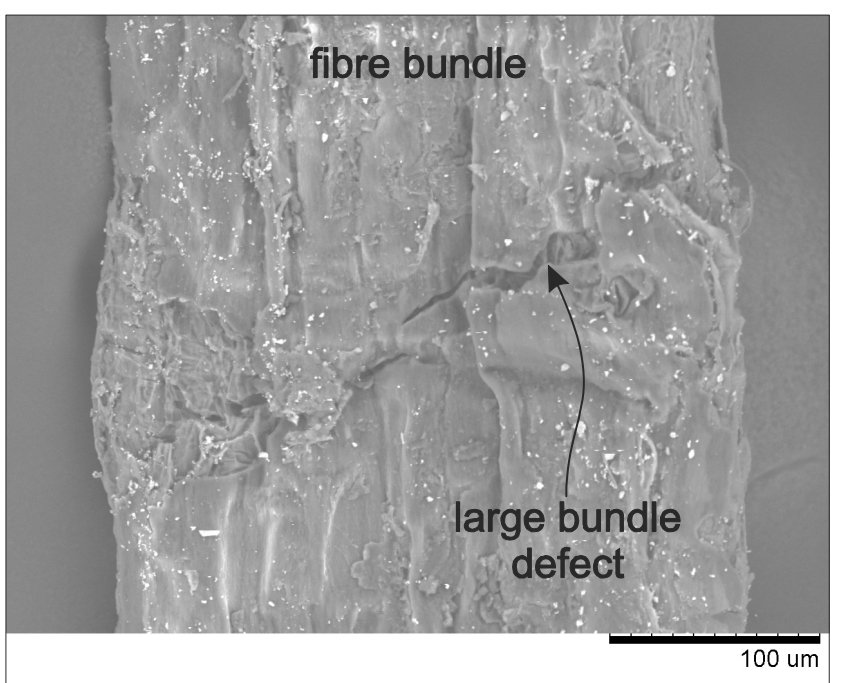

